\title{
Pengaruh Penggunaan Media Sempoa Geometri pada Kemampuan Berhitung Tunagrahita
}

\author{
Ninik Usfatun Chasanah, Rizqi Fajar Pradipta \\ Universitas Negeri Malang \\ E-mail: ninikusfatunanugrah@gmail.com
}

\begin{abstract}
Abstrak: Keterbatasan intelektual pada siswa tunagrahita menjadi permasalahan pembelajaran. Salah satu permasalahan yang dihadapi siswa tunagrahita adalah kesulitan siswa tunagrahita dalam berhitung penjumlahan bilangan $1-10$. Penelitian ini bertujuan untuk menerapkan media sempoa geometri yng dapat mengatasi permasalahan berhitung penjumlahan bilangan $1-10$ pada anak tunagrahita. Metode penelitian eksperimen dengan menggunakan uji hipotesis, rancangan penelitian one group pre test post test design yaitu (1) pre test (2) treatment (3) post test. Hasil rata - rata nilai seluruh siswa tunagrahita pada pre test dan post test adalah 52,00 dan 84,00 . Disimpulkan bahwa media sempoa geometri berpengaruh terhadap kemampuan berhitung penjumlahan bilangan 1 - 10 pada siswa tunagrahita kelas IV SDLB jombatan VII Jombang.

Kata kunci: Kemampuan berhitung; media sempoa geometri; tunagrahita
\end{abstract}

Abstract: The intellectual limitations of the intellectual disability students become a learning problem. One of the problem of the intellectual disability students is difficulty of counting the numbers of 1 until 10. This research aim is to apply the geometrical abacus media that can overcome the counting problems of the number 1 until 10 of the intellectual disability children. The steps of this experimental research method using hypothesis test, research design one group pre test post test design are: (1) pre test (2) treatment (3) post test. The average result of all intellectual disability students on pre test and post test was 52.00 and 84.00. It was concluded that the geometrical abacus media had an effect on the counting ability of number 1 until 10 in the students grade IV of SDLB VII Jombang.

Keywords: Ability to Calculate; Geometrical Abacus; Student with Intellectual disability

Pendidikan merupakan hak setiap warga Negara Indonesia, siapapun berhak mendapatkan layanan pendidikan

yang layak dan berkualitas. Melalui pendidikan seseorang dapat mengembangkan potensi yang ada dalam dirinya secara optimal. Pada hakekatnya hak anak untuk mendapatkan pendidikan adalah hak asasi manusia yang harus dihormati, dilindungi dan dipenuhi oleh Negara. Di Indonesia khususnya penyandang disabilitas tidak terhitung jumlahnya namun banyak yang belum mendapatkan pendidikan yang layak. Pendidikan yang diberikan kepada penyandang disabilitas maupun anak - anak reguler pada umumnya harus diberikan hak yang sama sehingga penyandang disabilitas juga dapat mengoptimalkan potensi yang masih bisa dikembangkan.

Seiring perkembangan dunia pendidikan, kehadiran siswa berkebutuhan khusus membuat pendidik dituntut untuk kreatif dalam memberikan pembelajaran pada anak - anak berkebutuhan khusus, salah satunya adalah siswa dengan hambatan intelektual atau tunagrahita. Siswa tunagrahita mengalami kesulitan belajar secara akademik (bahasa dan aritmatika atau matematika), kesulitan dalam hubungan interpersonal, kesulitan dalam mengurus diri, kesulitan dalam menilai situasi, ketergantungan kepada orang lain, serta belum mendapat perhatian yang memadai. Untuk materi pelajaran siswa tunagrahita kelas rendah hanya mampu menerima pelajaran seperti anak TK mencakup menebali, menempel, menyanyi. Sedangkan untuk kelas tinggi siswa tunagrahita mampu menerima materi seperti anak SD kelas rendah mencakup menulis, membaca, menggambar, mewarnai. Meskipun kemampuan kognitif siswa tunagrahita dalam kategori rendah namun keterampikan berhitung harus tetap dipelajari oleh siwa tunagrahita karena nantinya akan menjadi bekal hidupnya, sebab behitung selalu ada dalam kehidupan sehari - hari manusia. Oleh karena itu dalam pembelajaran konsep berhitung harus di desain dengan menggunakan media, agar pembelajaran yang diberikan dapat tersampaikan dengan baik.

Media yang digunakan juga harus sesuai dengan kebutuhan dan kemampuan siswa tunagrahita. Media pembelajaran sempoa geometri dirancang untuk membuat siswa tunagrahita lebih tertarik belajar menghitung penjumlahan, dengan media yang warnanya mencolok, dapat dipegang serta dapat digunakan berkali kali. "Sempoa Geometri" dapat dijadikan media pembelajaran dalam mata pelajaran berhitung salah satunya untuk memberikan konsep pemahaman berhitung penjumlahan melalui bentuk geometri. Belajar dengan menggunakan media pembelajaran sempoa geometri dapat membantu siswa tunagrahita untuk memecahkan soal - soal penjumlahan dengan mudah. Media sempoa geometri di buat dengan desain 3 dimensi sehingga dapat di pegang oleh siswa tunagrahita secara mudah menggunakan. 
Tabel 1. hasil pre test siswa tunagrahita

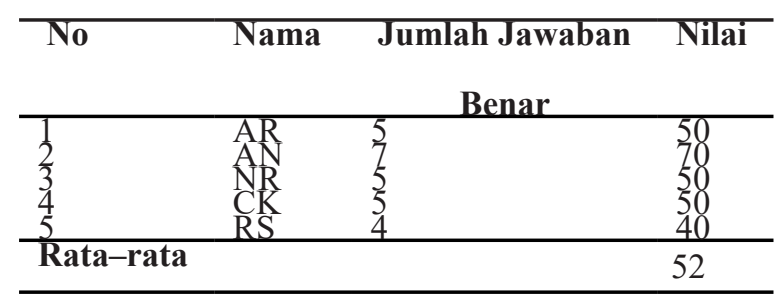

Tabel 2 hasil post test siswa tunagrahita

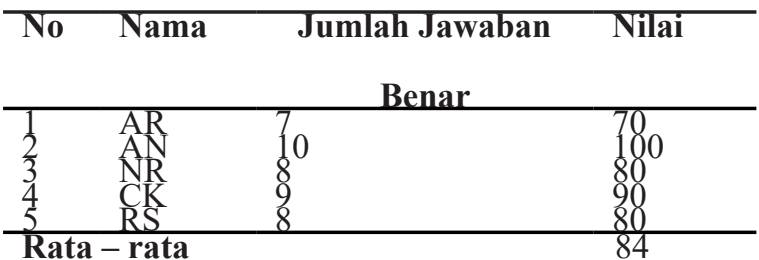

Tabel 3 hasil dari uji hipotesis

\begin{tabular}{llllll}
\hline Kelas & N & Mean & Sig & $\alpha$ & Kesimpulan \\
\hline Sebelum & 5 & 52,00 & 0,01 & 0,05 & Ada Pengaruh \\
\hline Sesudah & 5 & 84,00 & & & \\
\hline
\end{tabular}

Peneliti mencari penelitian terdahulu tentang media sempoa sebagai media pembelajaran dalam berhitung penjumlahan. Hasil dari penelitian menunjukan adanya peningkatan terhadap kemampuan menghitung penjumlahan bilangan 1 sampai 10 . Sempoa merupakan alat kuno yang terbuat dari manik - manik dengan menggeserkan kekiri dan kekanan. Tujuan penelitian adalah untuk mendeskripsikan kemampuan berhitung tunagrahita kelas IV SDLB sebelum diberikan treatment media sempoa geometri, untuk mendeskripsikan kemampuan berhitung tunagrahita kelas IV SDLB setelah diberikan treatment media sempoa geometri, dan untuk mengetahui pengaruh penggunaan media sempoa geometri terhadap kemampuan berhitung siswa tunagrahita kelas IV SDLB

\section{METODE}

Rancangan penelitian yang digunakan adalah eksperimen, Menurut Wiyono (2007) Penelitian eksperimen merupakan penelitian yang dilakukan dengan memberikan perlakuan kepada subyek yang akan diteliti diikuti dengan pengukuran terhadap akibat dari perlakuan. Penelitian eksperimen merupakan penelitian kuantitatif. Menurut Wiyono (2007) Penelitian kuantitatif adalah penelitian yang bersifat obyektifyang dapat diukur. Penelitian ini menggunakan penelitian pre - experimental design. Pre-experiment design Menurut Wiyono (2007) rancangan eksperimen hanya memperlakukan kelompok eksperimen saja, tanpa kelompok kontrol. Rancangan penelitian ini menggunaan one group pretest - posttest design, pada design ini terdapat pretest sebelum di beri perlakuan dan pada prosttest setelah diberi perlakuan akan diketahui hasilnya. Subjek penelitian ini adalah siswa - siswi kelas IV tunagrahita SDLB Jombatan VII Jombang sebanyak 5 orang.

Teknik pengumpulan data meliputi tahap persiapan yaitu dengan menyusun RPP kelas IV tunagrahita, tahap pelaksaan yang dilaksanakan pada bulan Februari kurang lebih satu bulan, dan tahap pengumpulan data yaitu data hasil belajar siswa yang diperoleh dari hasil pre test dan post test. Analisis data yaitu dengan menggunakan uji hipotesis untuk mengetahui perbedaan kemampuan berhitung penjumlahan bilagan 1 sampai 10 siswa tunagrahita kelas IV SDLB. Uji hipotesis dilakukan dengan menggunakan bantuan SPSS 16.0 dengan menggunakan uji paired sample $t$ - test.

\section{HASIL DAN PEMBAHASSAN}

\section{Hasil}

Data yang dikumpulkan oleh peneliti dari hasil penelitian pengaruh penggunaan media sempoa geometri terhadap kemampuan berhitung tunagrahita kelas IV SDLB Jombatan VII Jombang meliputi data pre test dan post test kemampuan berhitung penjumlahan bilangan 1 sampai 10 dengan menggunakan media sempoa geometri. Dari tabel 1 dapat diketahui bahwa rata - rata hasil pre test siswa tunagrahita dalam berhitung penjumlahan bilangan $1-10$ adalah sebesar 52. Nilai pre test siswa tunagrahita didapat sebelum adanya treatment dengan menggunakan media sempoa geometri. Dari tabel 2 dapat diketahui bahwa rata rata hasil post test siswa tunagrahita dalam berhitung penjumlahan bilangan 1 - 10 adalah sebesar 84 . Nilai post test siswa tunagrahita didapat setelah adanya treatment dengan menggunakan sempoa geometri. Berdasarkan tabel 3 hasil Uji Hipotesis dengan menggunakan Uji Paired Sample T - Test maka dapat disimpulkan bahwa nilai signifikansi 0,01<0,05 maka dapat dinyatakan bahwa terdapat perbedaan yang signifikan antara data pre test dan data post test.

Hasil uraian diatas dapat disimpulkan bahwa rata - rata hasil belajar yang dicapai oleh siswa tunagrahita setelah menggunakan media sempoa geometri pada pembelajaran berhitung penjumlahan 1 sampai 10 mengalami peningkatan daripada rata - rata hasil belajar sebelum menggunakan media sempoa geometri. Maka dapat ditarik kesimpulan bahwa $\mathrm{H} 0$ ditolak dan $\mathrm{H} 1$ diterima yang berarti bahwa adanya pengaruh secara signifikan pada pembelajaran berhitung penjumlahan 1 sampai 10 dengan menggunakan media sempoa geometri. Oleh karena itu media sempoa geometri yang diajarkan kepada siswa tunagrahita mempunyai pengaruh untuk materi berhitung penjumlahan 1 sampai 10 pada siswa tunagrahita kelas IV SDLB Jombatan VII Jombang. 


\section{Gambar 1 siswa mengerjakan soal pre test dan post test}

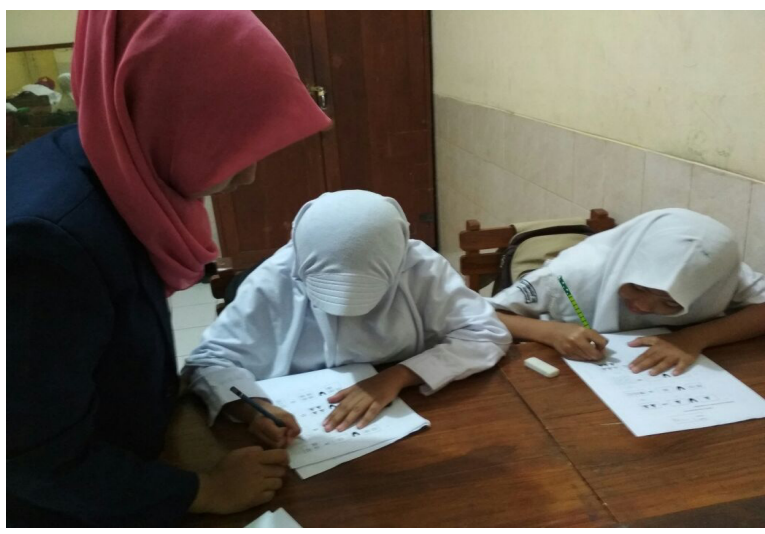

Gambar 2 siswa melakukan treatment dengan menggunakan media sempoa geometri

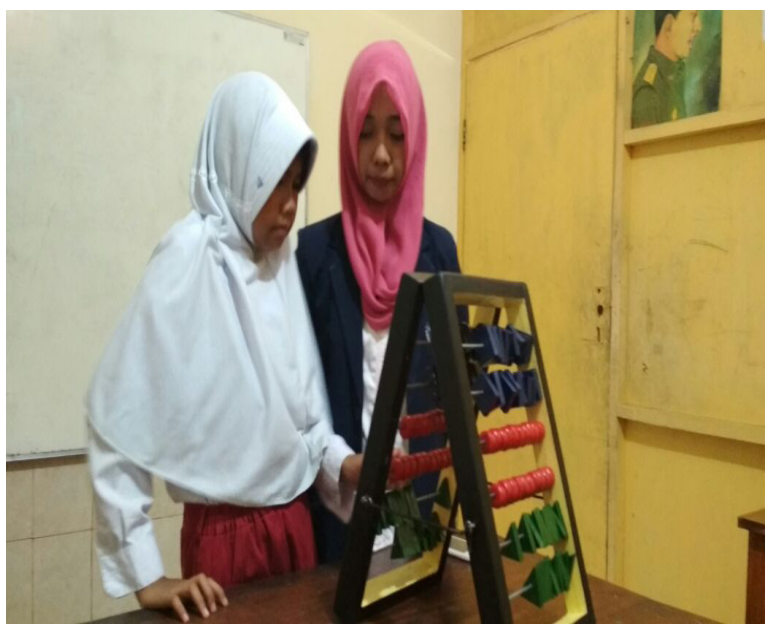

\section{Pembahasan}

Kemampuan siswa sebelum dilakukan perlakuan ( Pre test)

Menurut Khanifatul (2012) media pembelajaran berarti segala sesuatu yang dapat digunakan untuk menyalurkan bahan pembelajaran sehingga dapat merangsang perhatian, minat, pikiran, dan perasaan siswa untuk mencapai tujuan pembelajaran. Berdasarkan hasil dari pre test ada beberapa siswa yang kesulitan dalam hal berhitung. Menurut Suparman (2015) Berhitung adalah pelajaran yang umum berupa konsep yang abstrak sehingga memerlukan suasana belajar yang kondusif bagi peserta didik tunagrahita. Saat pemberian pre test ada peserta didik yang mengalami kesulitan Karena mereka mengganggap bahwa berhitung adalah sulit dan guru kelas pun sebelumnya memberikan materi berhitung penjumlahan hanya dengan menggunakan jari tangan tanpa menggunakan bantuan media apapun. Sehingga nilai pre test peserta didik masih rendah karena konsep pembelajaran berhitung penjumlahan yang dikuasai oleh siswa tunagrahita belum maksimal. Kemampuan awal peserta didik tunagrahita pada berhitung penjumlahan 1 sampai 10 sebelum diberikan treatment adalah menunjukkan hasil dari nilai rata rata sebesar 52, dengan nilai sebagai berikut : 50, 70, 50, 50 dan 40 dengan hasil rata - rata 52. Saat sebelum di berikan treatment kondisi peserta didik tunagrahita cenderung untuk enggan belajar matematika karena menganggap matematika itu sulit. Dua dari peserta didik saat sebelum diberikan treatment sangat sulit sekali diarahkan untuk menyelesaikan soal pre test, siswa yang bernama NR cenderung sibuk mencari perhatian kepada peneliti, sedangkan siswa bernama AR cenderung senang mencoret - coret lembar soal bila sesekali tidak dilihat oleh peneliti. Oleh karena hal itu peneliti membutuhkan waktu yang lama agar soal yang dikerjakan oleh kedua peserta didik itu dapat terselesaikan. Kemampuan peserta didik saat belum diberikan treatment mereka cenderung kurang menguasai dalam konsep bilangan 1 sampai 10 dan juga konsep bentuk bangun geometri yang meliputi bentuk persegi, lingkaran dan segitiga.

Kemampuan siswa tunagrahita setelah diberikan perlakuan ( Post test)

Menurut Sudjana \& Rivai (2015)Media pembelajaran ada dalam komponen metode mengajar sebagai salah satu upaya untuk mempertinggi proses interaksi guru - siswa dan interaksi siswa dengan lingkungan belajarnya. Kemampuan berhitung pada anak tunagrahita memang tidak semuanya sama, kemampuan mereka memang berbeda beda dengan teman yang lain (Wardhani \& Iriyanto, 2014). Pada saat pemberian treatment, Indikator kemampuan berhitungnya adalah sebagai berikut (1) membedakan konsep bilangan 1 sampai 10 dengan benar, (2) menjumlahkan bilangan 1 sampai 10 dengan bantuan sempoa geometri dengan benar, (3) menjumlahkan bilangan 1 sampai 10 tanpa bantuan sempoa geometri, (4) menulis hasil penjumlahan dengan benar. Hal tersebut menunjukkan hasil post test yang memiliki nilai rata - rata 84 dengan nilai sebagi berikut : 70, 100, 80, 90, dan 80. Setelah diberikan treatment mengalami peningkatan dari pre test yang memiliki nilai rata - rata 52 dari hasil keseluruhan siswa tunagrahita.

Kondisi siswa tunagrahita setelah diberikan treatment mengalami peningkatan,siswa tunagrahita menjadi semangat untuk belajar berhitung penjumlahan 1 sampai 10 dengan menggunakan sempoa geometri, mereka penasaran dengan media yang peneliti tunjukkan karena memang mereka sebelumnya berhitung hanya dengan menggunakan teori dari guru yaitu dengan menggunakan jari tanpa menggunakan media yang menarik. Menurut Setyaningrum \& Iriyanto (2014) melalui media pembelajaran yang menarik, anak tunagrahita akan antusias terhadap pembelajaran dikelas sehingga mereka memusatkan perhatian kepada guru yang menyampaikan materi.

Pengaruh Penggunaan Media Sempoa Geometri 
Terhadap Kemampuan Berhitung (Penjumlahan) pada Siswa Tunagrahita kelas IV

Menurut Rahmanita \& Samawi (2014) Kemampuan yang dapat dikembangkan pada anak tunagrahita antara lain : (1) membaca, menulis, mengeja dan menghitung, (2) menyesuaikan diri dan tidak menggantungkan diri pada orang lain, (3) keterampilan yang sederhana untuk kepentingan kerja dikemudian hari. Hasil dari data pre test dan post test pada subjek siswa tunagrahita kelas IV mengalami perubahana nilai rata - rata dari 52 ke 84. Perubahan tersebut menunjukkan dengan adanya pengaruh yang meningkat pada kemampuan berhitung (penjumlahan) bilangan 1 sampai 10 pada siswa tunagrahita kelas IV SDLB Jombatan VII Jombang. Hal itu tidak terlepas saat diberikan treatment sebanyak 3 kali yang dimulai dari pengenalan konsep bilangan 1 sampai 10, konsep bentuk geometri (segitiga, persegi dan lingkaran), dan cara menjumlahkan bilangan 1 sampai 10. Selain dengan adanya nilai yang meningkat, pengaruh penggunaan media sempoa geometri ini juga menunjukkan perubahan sikap siswa yang semangat berhitung dengan sempoa geometri, mereka antusias angkat tangan saat diminta peneliti untuk berhitung menggunakan sempoa geometri. Pada saat treatment peneliti juga meminta siswa untuk menulis di papan tulis secara bergantian yang dimulai dengan menulis bilangan 1 sampai 10 dan menggambar bentuk geometri yang meliputi bentuk persegi, segitiga dan lingkaran, serta sedikit pengenalan warna yang terdapat pada sempoa geometri. Hal itu sangat menunjukkan antusias siswa dalam mengikuti pembelajaran berhitung penjumlahan.

Berhasilnya dari penelitian ini adalah semangatnya siswa dan keingintahuannnya siswa pada saat penelitian berlangsung sehingga materi yang diberikan oleh peneliti dapat diterima dan tersampaikan dengan baik oleh siswa tunagrahita dan hal tersebut terbukti saat hasil post test siswa tunagrahita meningkat. Media sempoa geometri yang digunakan peneliti pada saat pembelajaran berhitung penjumlahan mengalami perubahan pada nilai yang didapat oleh siswa dan kondisi siswa tunagrahita yang semangat dan senang. Memberikan materi pembelajaran dengan menggunakan media pembelajaran yaitu berupa pemberian arahan serta contoh menjadi bagian terpenting pada penyelesaian berhitung penjumlahan siswa tunagrahita.

\section{KESIMPULAN DAN SARAN}

\section{Kesimpulan}

Hasil penelitian secara keseluruhan menunjukkan bahwa penggunaan media sempoa geometri terhadap kemampuan berhitung tunagrahita kelas IV dapat memberikan pengaruh. Pengaruh dapat ditunjukkan yaitu dengan adanya peningkatan dari hasil post test yang didapat oleh setiap siswa. Kemampuan berhitung penjumlahan bilangan $1-10$ yang rendah sebelum diberikan treatment dan mengalami peningkatan setelah diberikan treatment. Rendahnya kemampuan berhitung penjumlahan 1 - 10 pada siswa tunagrahita dikarenakan pembelajaran yang hanya ceramah dan monoton serta guru menyampaikan materi berhitung hanya dengan bantuan jari tangan tanpa menggunakan media apapun. Adanya pengaruh penggunaan media sempoa geometri adalah siswa menjadi antusias untuk berhitung penjumlahan bilangan $1-10$, dengan media yang warnanya menarik, dapat dipegang serta bentuk - bentuk bangun geometri. Pembelajaran dengan menggunakan media sempoa geometri menciptakan suasana belajar yang menyenangkan karena siswa dapat praktek secara langsung.

\section{Saran}

Dari hasil penelitian yang telah dilakukan, guru dan sekolah dapat menerapkan media sempoa geometri sebagai media pembelajaran di dalam kelas sehingga dapat meningkatkan pada hasil belajar berhitung dan memudahkan siswa tunagrahita dalam pembelajaran matematika khususnya penjumlahan.

\section{DAFTAR RUJUKAN}

Khanifatul. (2012). Pembelajaran Inovatif. Yogyakarta : Ar - Ruzzmedia

Rahmanita, F. \& Ahmad, S. (2014). Penggunaan Media Kartu Bilangan Untuk Meningkatkan Pembelajaran Matematika Anak Tunagrahita Di $S D L B$. Jurnal Ortopedagogia

Ronalis. (2015). Efektivitas Media Sempoa Untuk Meningkatkan Kemampuan Penjumlahan Bilangan Bulat 1 - 10 Untuk Anak Tunagrahita Ringan kelas II C SLB Fanredha Padang, (Online), Diakses tanggal 17 November 2017

Sudjana, N., \& Rivai, A. (2015). Media Pengajaran. Bandung : Algesindo

Styaningrum, T. L \& T. Iriyanto. (2014) Pengaruh Penggunaan Media Dakon Terhadap Kemampuan Berhitung Penjumlahan Siswa Kelas IV Tunagrahita Di SDLB Dharma Purta Daha Gurah Kediri. Jurnal Ortopedagogia

Suparman, S. (2015). Peningkatan Kemampuan Berhitung pada Anak Tunagrahita Ringan Melalui Media Permainan Kartu. (Online) Diakses Tanggal 09 Januari 2018

Wardani, R. Y, \& Tomas, I. (2014). Pengaruh Permainan Dadu Terhadap Kemampuan Berhitung Penjumlahan Anak Tunagrahita Kelas I SLB. Jurnal Ortopedagogia

Wiyono, B. B. (2007). Metode Penelitian. Malang : Universitas Negeri Malang 